\title{
Charcott-Marie-Tooth Disease Type 4c Caused from a Pathogenic Homozygous c.1897delG (p.Ala633Profs * 12) Variation in The SH3TC2 Gene
}

\author{
Fatih Kurt' ${ }^{1}$ Mustafa Doğan², Recep Eroz ${ }^{3}$ \\ 1 Duzce University, Pediatrics Clinic, Duzce, Turkey \\ 2 Turgut Ozal Research and Education Hospital, Genetics Clinic, Malatya, Turkey \\ ${ }^{3}$ Assoc. Prof., Duzce University, Genetics Clinic, Duzce, Turkey
}

*Corresponding Author: Dr. Fatih KURT, Department of Pediatrics, Duzce Ataturk State Hospital, Turkey -81000 .

E-mail: fatihkurt 04@hotmail.com, Phone: +90 5058380470

\begin{abstract}
Charcot-Marie-Tooth (CMT) is a group of diseases with peripheral nerve involvement known as hereditary sensory and motor neuropathy (1). It is the most common inherited neuromuscular disorder. CMT usually begins to show symptoms in the first 10 years and 20 s. Clinical symptoms are bilateral, symmetrical sensory and motor polyneuropathy. Its diagnosis is based on clinical findings, EMG and molecular genetic tests. Its treatment is symptomatic. In this article, a CMT Type 4c patient with scoliosis, kyphosis, bilateral sensory and motor polyneuropathy and having SH3TC2 mutation, which is very rare in genetic analysis, is presented.
\end{abstract}

Keywords: Charcott-Marie-Tooth, SH3TC2 Gene, Polyneuropathy, Axonal Demyelination, Electromyography.

\section{INTRODUCTION}

Charcot-Marie-Tooth disease (CMT) is a group of diseases with peripheral nerve involvement known as hereditary sensory and motor neuropathy ${ }^{[1]}$. It was first described by Charcot and Marie in Paris and Tooth in London in 1886 [2]. It is the most common hereditary neuromuscular disorder, seen at a rate of $1 / 2500$ in the general population ${ }^{[3,4]}$. The first clinical signs of CMT are seen in the distal feet and legs due to motor involvement. Bilateral and symmetrical atrophy of the muscles in the calf region, drop foot, pes cavus rarely pes planus, hammer toe deformity in the big toe are observed. Loss of reflex is detected on examination. Depending on the severity of the sensory involvement, painless callus and foot ulcers, lymphangitis, erysipelas, osteonecrosis in some types, and self-amputations appear ${ }^{[5]}$.

CMT has many forms. The most common forms are CMT1, CMT2, СMT3, CMT4 and CMTX ${ }^{[2]}$. In this article, a patient with scoliosis, kyphosis, bilateral sensory-motor polyneuropathy and diagnosed as CMT Type $4 \mathrm{c}$ by detecting a pathogenic homozygous c.1897delG (p.Ala633Profs * 12) variant in the SH3TC2 gene in genetic analysis is presented.

\section{CASE REPORT}

A 12 year old female patient was referred to our clinics after the pescavus and pes varus operation. In his history, it was learned that he did not have any complaints until the age of 7 , and that the complaints of kyphosis, scoliosis and fatigue began around the age of 7. It was learned that the patient's kyphosis and scoliosis progressed. He stated that he had numbness and weakness in his extremities and that his foot structure had changed. He had been operated for pes cavovarus by orthopedics. The patient goes to school and was successful in his lessons. It was learned that there were no patients with similar complaints in the family. The patient was conscious, mentally good and gave appropriate answers to the questions. On physical examination, the oropharynx and ears were natural, respiratory and heart sounds were natural, and there was no additional sound or murmur. Eye tracking was limited. There was scoliosis with the opening pointing to the left at the thoracic level and to the right at the lumbar level, and kyphosis in the upper thoracic (Figure $1 \mathrm{a}$ ). The patient's muscle strength in the distal muscles was $4 / 5$, deep tendon reflexes could not be obtained bilaterally, babinski was indifferent. The patient's right foot was more atrophic than the left (Figure $1 \mathrm{~b}$ ). He had muscle atrophy 
in both hands (Figure $1 \mathrm{c}$ ).

Hearing and visual examinations were normal. The patient's metabolic screening tests and brain MRI were normal. Thoracolumbar MR was compatible with scoliosis and kyphosis, there was no additional pathology. It was learned that sensory and motor neuropathy with axonal demyelination and damage were detected in electromyography. Family pedigree of the patient was given in Figure 2. As a result of the genetic analysis performed due to the etiology of hereditary neuropathy, a homozygous c.1897delG (p.Ala633Profs * 12) variant in the SH3TC2 gene was detected and the diagnosed as Charcott Marie Tooth Type 4c. After the operation, family members of the proband who were receiving physical therapy were screened for this change by Sanger sequencing. The same variants were detected as heterozygous state in both parents and sister of proband (Figure 3). The genetic counseling was given to the family regarding the molecular analysis results. The pathogenicity data for the identified variant were given in Table 1.
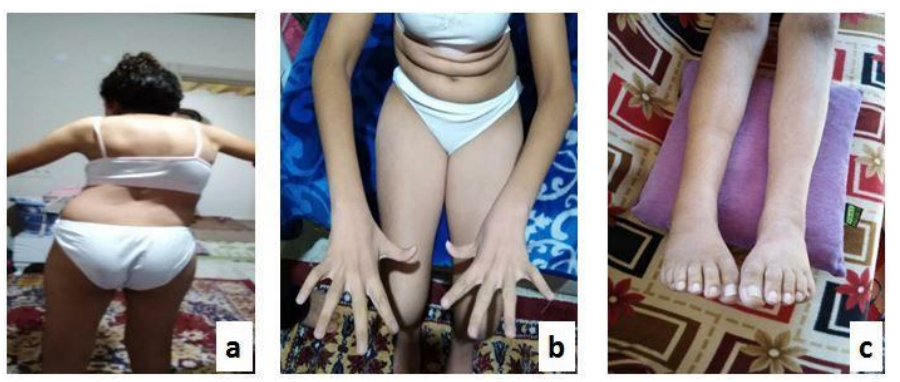

Figure 1: The patient's kyphoscoliosis (a), atrophic hand findings (b), atrophic right lower extremity (c).

\section{Discussion}

Charcot-Marie-Tooth (CMT), a group of diseases, referred to by chronic motor and sensory polyneuropathy known as hereditary motor and sensory neuropathy (HMSN). There are different inheritance form as autosomal dominant, autosomal recessive,

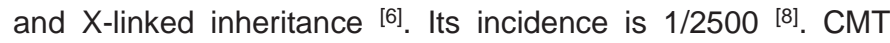
usually begins to show symptoms in the first 10 years and 20 s. Muscle weakness and atrophy are seen primarily as a result of distal motor neuropathy in the hands and feet. Pes cavus, hammer toes, walking difficulty, drop foot, weakness and sensory loss in the distal segments of the lower and then upper extremities, decreased or disappeared deep tendon reflexes are the known basic findings of CMT [5]. CMT Type4c is an autosomal recessive type. The most common findings are scoliosis and foot deformities. Scoliosis is seen in $73 \%$ of CMT Type4c patients, and foot deformities are seen in $72-100 \%$. In addition, it has been reported in the literature that sensorineural hearing loss is $11-14 \%$, respiratory problems are $18 \%$, and cranial nerve involvement is $45 \%{ }^{[7]}$.
Its diagnosis is based on clinical findings, EMG and molecular genetic tests. Its treatment is symptomatic. Physical therapy is very important both in preventing the development of deformity and in preventing secondary complications such as shortening of the Achilles tendon. Special shoes and orthotic devices can be used for low foot and foot deformities. Surgery may be required for spinal deformities and foot deformities. The onset and progression of scoliosis, the function of the hands and the strength of the feet should be monitored. Genetic counseling should definitely be given to the family ${ }^{[9]}$.

In the differential diagnosis, acquired causes (vitamin B12 deficiency, B6 deficiency, diabetes, neuropathy due to kidney disease, Guillain-Barré Syndrome, Sarcoidosis, Leprosy, Lyme, HIV, neoplasia, drugs, toxins, amyloidosis, etc.) and hereditary causes (CMT, Hereditary sensory -atonoma neuropathy, Familial amyloidosis, Porphyria, Fabry disease, metachromatic leukodystrophy, adrenoleukodystrophy, Refsum disease, Spinal muscular atrophy, Familial amyotrophic lateral sclerosis, etc.) were considered. Hereditary neuropathies begin at an earlier age than acquired neuropathies, and clinical findings show a very slow and progressive course, despite the detection of motor, sensory and / or autonomic system losses in neurological examinations ${ }^{[10] .}$

\section{CONCLUSION}

In the light of this information, hereditary reasons were considered in the foreground. In the history of our patient, exercise intolerance that started in the first decade, presence of kyphoscoliosis and progression, development of pes cavus and pes varus in the follow-up, motor and sensory neuropathy in EMG made the pre-diagnosis of Charcott-Marie-Tooth disease, which is the most common cause of hereditary polyneuropathy. Hereditary neuropathy genes were studied with next-generation sequencing and the patient was found to have a homozygous c.1897delG (p.Ala633Profs * 12) pathogenic variant in the SH3TC2 gene. The patient was diagnosed with CMT Type4c with clinical and molecular findings.

Table 1: The pathogenicity data for the identified variant

\begin{tabular}{|l|l|}
\hline GENE & SH3TC2 \\
\hline Transcript ID & NM_024577.4 \\
\hline dbSNP & rs1064797314 \\
\hline Variant & c.1897delG (p.Ala633ProfsTer12) \\
\hline Variant location & Exon 11 \\
\hline Variant type & Deletion-Frameshift \\
\hline gnomAD (exomes) & Not found \\
\hline ClinVar & Likely pathogenic \\
\hline Conservation & Conserved \\
\hline DANN score & Not found \\
\hline GERP score & NR: 6.0399; RS: 3.7749 \\
\hline ACMG classification & Pathogenic \\
\hline ACMG pathogenicity criteria & PVS1, PM2, PP3, PP5 \\
\hline
\end{tabular}




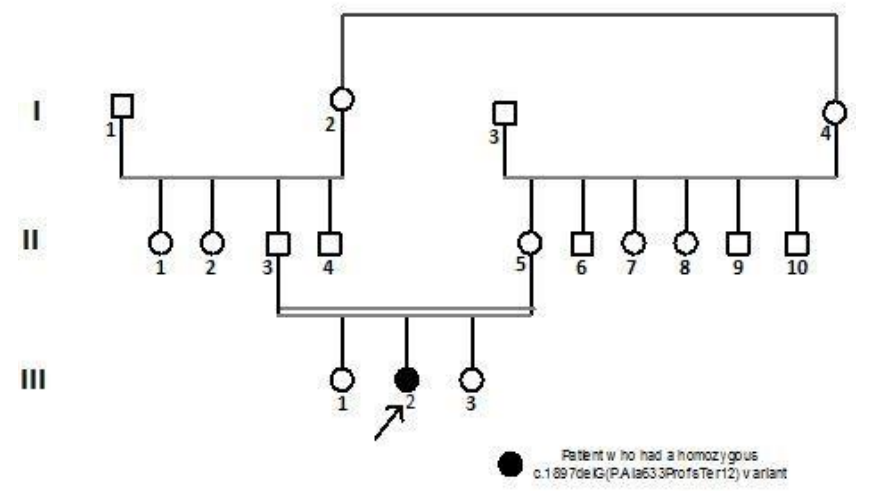

Figure 2: The family pedigree of proband with homozygous c.1897delG (p.Ala663ProfsTer12) variant. The pedigree comprises 17 members with three generations ( 7 males, 10 females). III-2 is proband and both $\mathrm{II}-3$ and II-5 are the parents. III-1 and III-3 are siblings of the proband

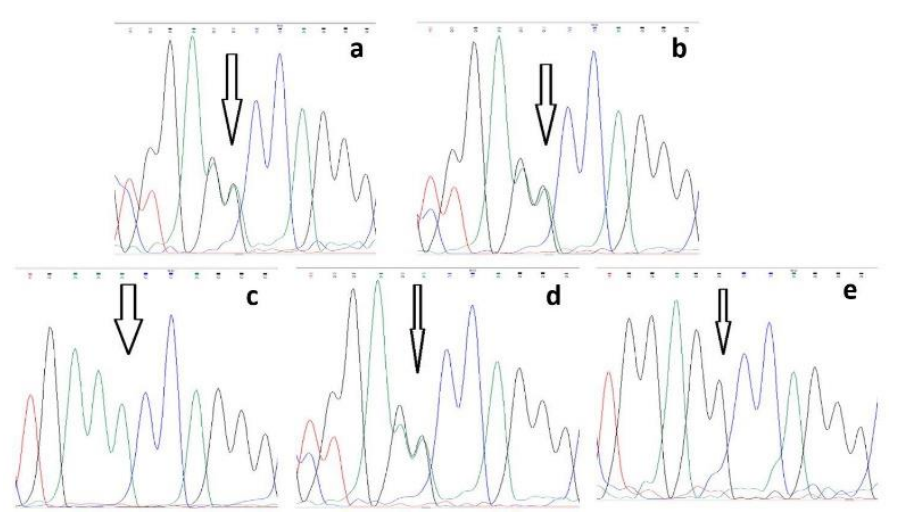

Figure 3: Sanger sequencing traces of the Family showing the presence of the c.1897delG (p.Ala663ProfsTer12) on the SH3TC2 gene in a homozygous state in the proband (c), heterozygous state in father (b), heterozygous state in mother (a), heterozygous state in sister (d) and normal in the brother (e).

\section{REFERENCES}

1. Høyer H, Braathen GJ, Eek AK, Nordang GBN, Skjelbred CF, Russell MB. Copy number variations in a population-based study of Charcot-Marie-Tooth disease. Biomed Res Int, 2015; 960404. https://doi.org/10.1155/2015/960404

2. Shy Michale E. Peripheral neuropathies. Merrit's Neurology. Ed. Lewis P. Rowland. 12. Philadelphia, Lippincott Williams and Wilkins, 2005; 733-47.

3. Vallat JM, Mathis S, Funalot B. The various Charcot-Marie-Tooth diseases. Curr Opin Neurol, 2013; 26(5):473-80. https://doi.org/10.1097/WCO.0b013e328364c04b

4. Kenis-Coskun O, Matthews DJ. Rehabilitation issues in CharcotMarie-Tooth disease. J Pediatr Rehabil Med, 2016; 9(1):31-4. https://doi.org/10.3233/PRM-160359

5. Garba C, Vogel HP, Tebbe B, Nüssel F, Marx P, Orfanor CE. Ulcero-mutilating acro-osteopathy in hereditary neuropathies. Differantial diagnosis and pathogenesis. Dtsch Med Wochenschr, 1989; 114(16):628-32. https://doi.org/10.1055/s-2008-1066647

6. Bird TD. Charcot-Marie-Tooth (CMT) Hereditary Neuropathy Overview, GeneReviews ${ }^{\circledR}$ [Internet]. Seattle (WA): University of Washington, Seattle; 1993-2021. 1998 Sep 28 [updated 2021 Mar 18].

7. Azzedine H, Ravisé N, Verny C, Gabrëels-Festen A, Lammens M, et al. Spine deformities in Charcot-Marie-Tooth $4 \mathrm{C}$ caused by
SH3TC2 gene mutations. Neurology, 2006; 67(4):602-6. https://doi.org/10.1212/01.wnl.0000230225.19797.93

8. Jani-Acsadi A, Ounpuu S, Pierz K, Acsadi G. Pediatric CharcotMarie-Tooth disease. Pediatric Clinics of North America, 2015; 62(3):767-86. https://doi.org/10.1016/j.pcl.2015.03.012

9. Ichikawa K, Numasawa K, Takeshita S, Hashiguchi A, Takashima $\mathrm{H}$. Novel mutations in SH3TC2 in a young Japanese girl with Charcot-Marie-Tooth Disease Type 4C. Pediatr Int, 2016; 58(11):1252-4. https://doi.org/10.1111/ped.13152

10. Barohn RJ, Amato AA. Pattern-recognition approach to neuropathy and neuronopathy. Neurol Clin, 2013; 31:343-61. https://doi.org/10.1016/j.ncl.2013.02.001 